\title{
Pulverlackiermaschine mit neuem Shuttle-Fördersystem
}

fotek präsentiert auf dem Gemeinschaftsstand Praxispark-Kompetenzzentrum für Oberflächentechnik eine vollfunktionsfähige, vollautomatische Pulverlackier-

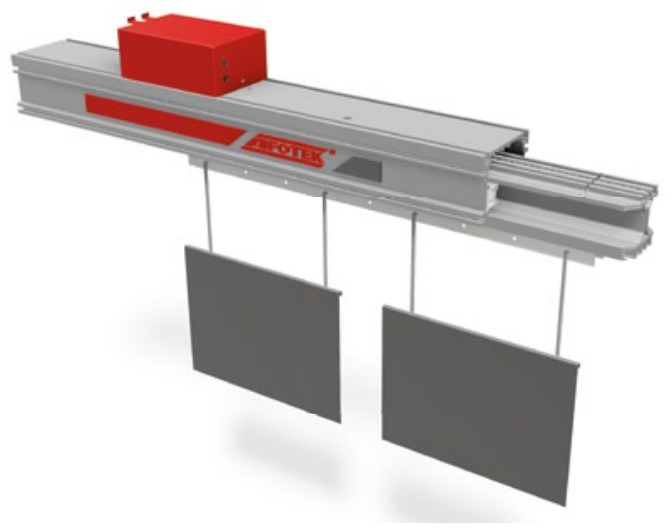

maschine in Zimmergröße mit einem neuen Shuttle-Fördersystem (ASF). Das neu entwickelte Transportkonzept für die Warenträger-Logistik bietet nach Angaben des Anlagenbauers maximale Flexibilität in mehrfacher Hinsicht: Durch den modularen und kompakten Aufbau lässt sich das System praktisch an alle räumlichen Gegebenheiten anpassen und jederzeit nach Bedarf erweitern oder modifizieren. Die bisher übliche „Endlos-Förderkette“ wird mit dem neuen Transportsystem in einzelne, individuell steuerbare Förderelemente aufgeteilt, die sich zudem in jede gewünschte Richtung fahren lassen - unabhängig voneinander, positionsgenau und in unterschiedlichen Geschwindigkeiten. Das System sauber und wartungsfrei, was zu einer spürbaren Reduzierung der Betriebskosten beiträgt.

Tel. 06621 5076-0, www.afotek.de

Halle 3, Stand E 14

\section{Selektive Chrom-Abscheidung}

A HC Oberflächentechnik, Kerpen, sieht in der AHC-Gruppe entwicklungsmäßig einen Trend hin zu selektiven Beschichtungsverfahren. Bei diesen Verfahren werden nur Teilbereiche eines Bauteils oberflächenbehandelt, ohne aufwändige Abdeckarbeiten. Bekannt ist bereits die partielle Hartanodisation von Aluminium-Bauteilen, wie zum Beispiel Motorkolben. Dieses unter dem Namen Selga-Coat am Markt eingeführte Verfahren wur- de nun in Zusammenarbeit mit AHC Benelux um die Variante Selga-Chrom erweitert. Hierbei werden Chromschichten in einem geschlossenen System, also ohne Beschichtungsbecken, auf Bauteilen aus unlegiertem oder gehärtetem Stahl aufgebracht. Bei Schichtdicken von $22 \pm 2 \mu \mathrm{m}$ werden Härten von 950-1.200 HV und ein guter Korrosionsschutz (240 Stunden im Salzsprühtest nach DIN EN ISO 9227) erreicht.

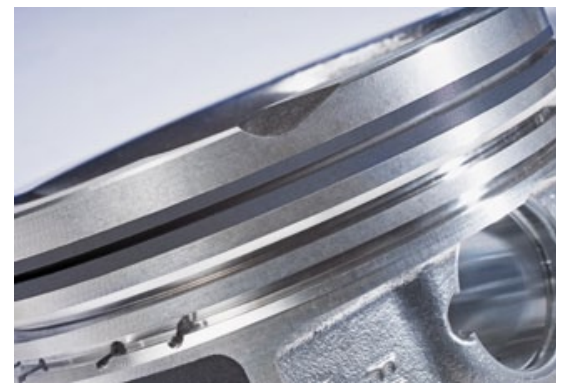

Tel. 02237 502-0, www.ahc-surface.com Halle 3, Stand C 59

\section{Inline-Überwachung der Netzmittelkonzentration}

Drozesssicherheit in der Oberflächentechnik ist Voraussetzung für qualitativ hochwertige Produkte. In den Reinigungs-, Vorbehandlungs- und Abscheideprozessen der nasschemischen Oberflächentechnik spielen Tenside und

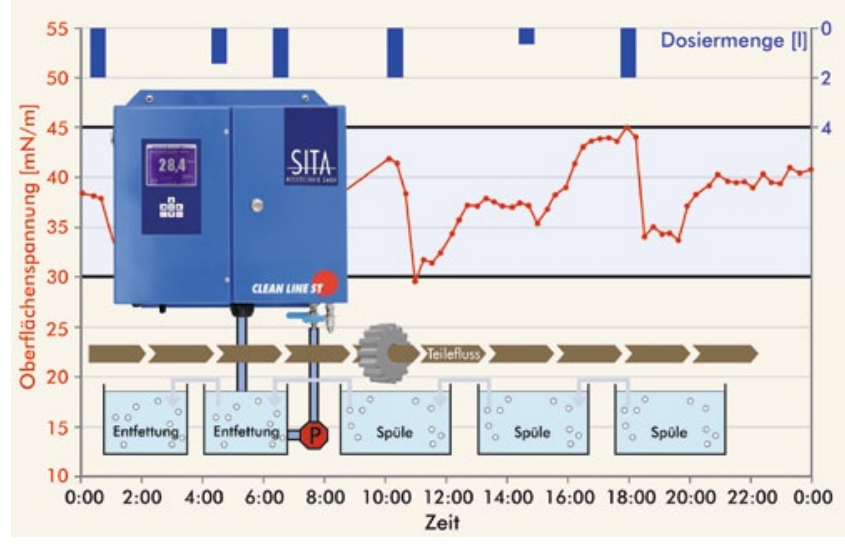

Netzmittel für die Qualität der Beschichtung eine wichtige Rolle. Da sich sowohl Unter- als auch Überdosierung der Tenside negativ auf die Schichtqualität und den Prozess auswirken, ist eine bedarfsgerechte Nachdosierung nötig. Dafür muss die Tensidkonzentration kontrolliert werden. Hierzu hat sich das Messen der dynamischen Oberflächenspannung mit der Blasendruckmethode weltweit bewährt. Sita Messtechnik hat ein robustes und flexibel anpassbares Prozesstensiometer ( clean line ST) zur kontinuierlichen und vollautomatischen Messung der Oberflächenspannung von Flüssigkeiten entwickelt. Nutzereingriffe sind nicht notwendig, das Reinigen und Kalibrieren erfolgt automatisch. In die Anlagensteuerung eingebunden, ermöglicht das Inline-Messsystem die bedarfsgerechte automatische Dosierung der Netzmittel in Abscheideprozessen oder des Reinigers in der Vorbehandlung. Tel. 0351 871-8041, www.sita-process.com Halle 3, Stand D 54(9) 